\title{
O perfil dos profissionais do magistério da Rede Municipal de Ensino de Curitiba
}

\author{
The teachers profile in Municipal Education Network of \\ Curitiba-PR, Brazil
}

\section{Diana Cristina de Abreu'}

\section{RESUMO:}

O artigo, partindo de uma categorização dos profissionais que exercem atividades docentes e não-docentes na Rede Municipal de Ensino de Curitiba, estabelece um perfil dos profissionais na capital paranaense. Os dados publicados são parte da dissertação de mestrado, concluída em 2008, pela autora, e apresentada na Linha de Pesquisa Políticas e Gestão da Educação do Curso de Pós-Graduação em Educação, da Universidade Federal do Paraná, intitulada "Carreira e perfil do profissional do magistério na Rede Municipal de Ensino de Curitiba: História e impacto da política brasileira de valorização do magistério". Para a construção do perfil utilizouse a Relação Anual de Informações Sociais do Ministério do Trabalho e Emprego e informações fornecidas ao Sindicato dos Servidores do Magistério Municipal de Curitiba pelas Secretarias Municipais de Educação e Recursos Humanos. Assim considerou-se para as análises a distribuição dos profissionais por sexo, idade, escolaridade, tempo de serviço, número de vínculos na RME e enquadramento na carreira.

PALAVRAS-CHAVE: Perfil do magistério;

Educação Básica; Profissionais da Educação.

\begin{abstract}
:
This article, beginning from a categorization of the professionals that practices teaching and non teaching activities in the Municipal Education Net of Curitiba, establishes a profile of those professionals in the capital of Parana state. The published data are part of a dissertation of master's degree, concluded in 2008, by the author, and presented in the Line of Politics Researches and Management of the Education of the Postgraduate Course in Education, at Federal University of Parana, titled as Career and profile of the primary school teaching professional in the municipal Net of Teaching of Curitiba: history and impact of the Brazilian politics of increase in value of school teaching. To construct the profile, it was used the Annual Relation of Social Informations of the Department of Labor and Job and Information given to SISMMAC by the Municipal General Offices of Education and Human Resources. Thus it was considered to the analyses a distribution of the professionals by genre, age, schooling, time of service, number of bonds in the RME and career situation.
\end{abstract}

KEYWORDS: Teachers Profile; Basic Education; Education workers. 


\section{Introdução}

Neste trabalho, para a análise e construção do perfil, consideram-se somente os profissionais do magistério, ${ }^{2}$ ou seja, professores e pedagogos da Rede Municipal de Ensino, cargo criado pela Lei n. ${ }^{\circ}$ 10.190/2001. Esse esclarecimento se faz necessário visto que a Confederação Nacional dos Trabalhadores em Educação utiliza a categoriza trabalhadores em educação para definir os sujeitos envolvidos nas atividades de docência e não-docência, vinculados direta ou indiretamente à atividade educativa. Estes profissionais podem atuar em Escolas Regulares, em Centros de Educação Integral, Centros Municipais de Educação Infantil, Escolas de Educação Especial, Faróis do Saber ${ }^{3}$ e Bibliotecas.

Para melhor definir o perfil dos profissionais do magistério em Curitiba, passar-se-á a utilizar os dados da RAIS 4 (Relação Anual de Informações Sociais do Ministério do Trabalho) de 1999, 2001, 2003 e 2005.

Foram consideradas essas datas porque nelas foram realizados concursos públicos e também porque elas contemplam tanto o período anterior quanto o posterior da aprovação do plano de carreira vigente para o magistério público em Curitiba.

Para comparação entre 0 perfil dos profissionais do magistério de Curitiba e o perfil do magistério brasileiro, far-se-á uso também dos dados publicados pelo INEP, na Sinopse do Censo dos Profissionais do Magistério da Educação Básica/2003.

Os profissionais do magistério segundo sexo, escolaridade, faixa etária, tempo de serviço, remuneração, carreira e jornada de trabalho
Sexo

A distribuição de profissionais do magistério da educação básica por sexo no Brasil é de $85 \%$ para o sexo feminino e de $15 \%$ para o sexo masculino. Já em Curitiba/2005, a distribuição era de $97,31 \%$ para o sexo feminino e de 2,69\% para o sexo masculino. Chama à atenção a significativa diminuição da participação masculina no quadro municipal quando comparado ao quadro nacional. Contudo, há uma razão lógica que explica esse quadro: quando se fala em números nacionais, englobam-se todos os níveis, da educação infantil ao ensino médio; quando se fala de Curitiba, fala-se de um universo predominantemente da educação infantil aos primeiros anos do ensino fundamental, apenas 11 estabelecimentos ofertam do $6^{\circ}$ ao $9^{\circ}$ ano e em nenhum deles é ofertado o ensino médio no município. Como a concentração de profissionais do magistério do sexo masculino, no quadro nacional e em geral, se dá nos anos finais do ensino fundamental e no ensino médio, tornase natural a aparente aberração que se observa ao comparar o quadro nacional com o de Curitiba.

Tabela 1 - Perfil dos profissionais do magistério - 1999, 2001, 2003 e 2005

\begin{tabular}{|c|c|c|c|c|}
\hline Ano & Sexo & Homens & Mulheres & Total \\
\hline \multirow{2}{*}{1999} & Empregos & 348 & 6.415 & 6.763 \\
\hline & Part.\% & 5,15 & 94,85 & 100,00 \\
\hline \multirow{2}{*}{2001} & Empregos & 247 & 6.504 & 6.751 \\
\hline & Part.\% & 3,66 & 96,34 & 100,00 \\
\hline \multirow{2}{*}{2003} & Empregos & 259 & 8.109 & 8.368 \\
\hline & Part.\% & 3,10 & 96,90 & 100,00 \\
\hline \multirow{2}{*}{2005} & Empregos & 255 & 9.219 & 9.474 \\
\hline & Part. \% & 2,69 & 97,31 & 100,00 \\
\hline
\end{tabular}

Fonte: RAIS/ MTE, elaboração Dieese

$2 \mathrm{Na}$ rede municipal estão presentes, também, os Educadores, que são docentes de que atuam na educação Infantil nos Centros de Educação Infantil, com carreira, remuneração e jornada de trabalho diferenciadas. A atuação, carreira e perfil desses profissionais, é um tema a ser estudado.

3 Os Faróis do Saber ou Bibliotecas de bairro prestam atendimento às escolas e à comunidade em geral. 0 conceito de farol, ou por razões de marketing ou por gostar da metáfora, estava tão decidido e impregnado na equipe que concebeu o espaço que até seu modelo arquitetônico lembra um farol. Atualmente a maioria dos profissionais que atuam nesses espaços é constituída por assistentes pedagógicos ou detentores de laudo médico definitivo, esta área de atuação foi prevista na Lei $n .^{\circ}$ 10.190/2001.

4 A Relação Anual de Informações Sociais - RAIS. Instituída pelo Decreto n. 76.900 , de 23/12/75, atualmente disciplinada pela Portaria . $^{\circ}$ 651de 2007, do Ministério do Trabalho e Emprego a RAIS tem por objetivo: o suprimento às necessidades de controle da atividade trabalhista no País; o provimento de dados para a elaboração de estatísticas do trabalho, a disponibilização de informações do mercado de trabalho às entidades governamentais. 
GRÁFICO 1 - Relação Mulheres e Homens no Magistério Público Municipal de Curitiba em 2005

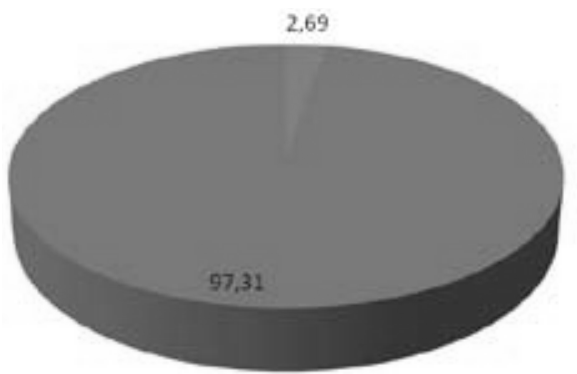

Womens

Mulheres

Estatísticas apontam, e é desnecessário repeti-las aqui, que no Brasil, mesmo no exercício da mesma atividade e com igual qualificação profissional, homens e mulheres recebem salários diferentes, em desfavor da mulher. No caso da prefeitura de Curitiba, uma hipótese para justificar o fato, é que os profissionais do sexo masculino atuam majoritariamente na docência II. ${ }^{5}$ Criadas a partir da Lei n. ${ }^{0}$ 10.190/2001, entre as docências I e II predominou uma diferença de remuneração de $31,71 \%$ para os profissionais que atuassem na docência II.

$\mathrm{Na}$ relação entre número de empregos e salários médios, observada a distribuição por sexo, constatamos na tabela 2, que os vencimentos dos profissionais do sexo masculino são superiores em todos os períodos analisados. Entretanto, essa diferenciação é mais expressiva em 2005, quando eles possuem uma média salarial de $R \$ 2.259,00$ e elas, de $R \$ 1.596,00$.

Tabela 2 - Perfil dos profissionais do magistério - 1999, 2001, 2003 e 2005

\begin{tabular}{|c|c|c|c|c|}
\hline Ano & Sexo & Homens & Mulheres & Total \\
\hline \multirow{2}{*}{1999} & Empregos & 348 & 6.415 & 6.763 \\
\hline & Sal. Médio & $1.167,90$ & $1.036,11$ & $1.042,89$ \\
\hline \multirow{2}{*}{2001} & Empregos & 247 & 6.504 & 6.751 \\
\hline & Sal. Médio & $1.501,21$ & $1.174,31$ & $1.186,27$ \\
\hline \multirow{2}{*}{2003} & Empregos & 259 & 8.109 & 8.368 \\
\hline & Sal. Médio & $1.795,95$ & $1.250,95$ & $1.267,82$ \\
\hline \multirow{2}{*}{2005} & Empregos & 255 & 9.219 & 9.474 \\
\hline & Sal. Médio & $2.259,00$ & $1.575,00$ & $1.596,00$ \\
\hline
\end{tabular}

Fonte: RAIS/TEM, elaboração Dieese
GRÁFICO 2 - Diferença salarial entre os sexos em 2005

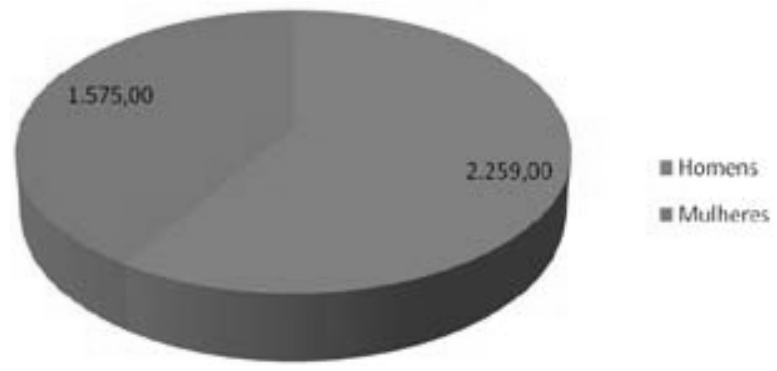

\section{Escolaridade}

A LDB recomenda para os sistemas de ensino que a condição de ingresso na carreira do magistério seja a formação em nível superior, entretanto admite-se a formação inicial na modalidade normal para os primeiros anos do ensino fundamental. A prefeitura de Curitiba, já em 2001, estabeleceu como condição de ingresso o nível superior. Analisando a tabela 3, observamos que $82,58 \%$ dos profissionais do quadro possuíam curso superior em 2005.

Tabela 3 - Perfil escolaridade - 1999, 2001, 2003 e 2005

\begin{tabular}{|c|c|c|c|c|c|}
\hline Ano & $\begin{array}{c}\text { Grau de } \\
\text { Instrução }\end{array}$ & $\begin{array}{c}2^{\circ} \text { grau } \\
\text { completo }\end{array}$ & $\begin{array}{c}\text { Superior } \\
\text { incompleto }\end{array}$ & $\begin{array}{c}\text { Superior } \\
\text { completo }\end{array}$ & Total \\
\hline 1999 & Empregos & 1.695 & 6.630 & 4.417 & 6.763 \\
\hline 2001 & Empregos & 2.237 & 7 & 4.491 & 6.751 \\
\hline 2003 & Empregos & 1.782 & 47 & 6.538 & 8.368 \\
\hline 2005 & Empregos & 1.616 & 32 & 7.824 & 9.474 \\
\hline
\end{tabular}

Fonte: RAIS/MTE, elaboração DIEESE

Em 1999 mais de 65\% do quadro próprio do magistério possuía curso superior completo e mais de $9 \%$ estava cursando este nível de ensino. Chama a atenção este fato, pois os profissionais ainda não tinham plano de carreira e não recebiam pela maior habilitação, critério de carreira extinto em 1991.

Já destacamos nesse trabalho que a formação exigida para o ingresso dos profissionais no magistério é um importante elemento para a qualidade educacional. A partir de 2001, mediante a Lei n. ${ }^{\circ}$ 10.190/2001, a titulação mínima exigida para ingresso na rede pública municipal de Curitiba passou a ser o terceiro grau. Da mesma forma, a legislação que disciplina e regulamenta as carreiras docentes tendeu a adotar esse princípio como um dos indicadores de qualidade, ainda 
que salvaguarde os direitos adquiridos daqueles que ingressaram sob outra lei. Em 2005, 82,58\% do quadro do magistério havia completado o curso superior; como o enquadramento pela maior habilitação não ocorre de forma automática, mediante a apresentação da titulação, mas depende de disponibilidade orçamentária e número de vagas fixado por lei, é comum encontrar profissionais que tenham a habilitação e não estejam com os vencimentos compatíveis com ela.

\section{Faixa etária}

No que se refere à faixa etária, a tabela 4 agrega as características do magistério municipal:

Tabela 4 - Perfil faixa etária - 1999, 2001, 2003 e 2005

\begin{tabular}{|c|c|c|c|c|c|c|c|c|}
\hline \multirow{2}{*}{$\begin{array}{c}\text { Faixa } \\
\text { Etária }\end{array}$} & \multicolumn{2}{|c|}{1999} & \multicolumn{2}{c|}{2001} & \multicolumn{2}{c|}{2003} & \multicolumn{2}{|c|}{2005} \\
\hline & Empregos & $(\%)$ & Empregos & $(\%)$ & Empregos & $(\%)$ & Empregos & $(\%)$ \\
\hline $\begin{array}{c}18 \mathrm{a} \\
24\end{array}$ & 334 & 4,94 & 189 & 2,80 & 261 & 3,12 & 111 & 1,17 \\
\hline $\begin{array}{c}25 \mathrm{a} \\
29\end{array}$ & 1.235 & 18,26 & 1.049 & 15,54 & 1.336 & 15,97 & 1.248 & 13,17 \\
\hline $\begin{array}{c}30 \mathrm{a} \\
39\end{array}$ & 2.064 & 30,52 & 2.207 & 32,69 & 3.143 & 37,56 & 3.830 & 40,43 \\
\hline $\begin{array}{c}40 \mathrm{a} \\
49\end{array}$ & 2.340 & 34,60 & 2.276 & 33,71 & 2.389 & 28,55 & 2.632 & 27,78 \\
\hline $\begin{array}{c}50 \mathrm{a} \\
64\end{array}$ & 778 & 11,50 & 1.023 & 15,15 & 1.230 & 14,70 & 1.630 & 17,20 \\
\hline $\begin{array}{c}65 \\
\text { ou + }\end{array}$ & 10 & 0,15 & 7 & 0,10 & 9 & 0,11 & 23 & 0,24 \\
\hline $\begin{array}{c}\text { Igno- } \\
\text { rado }\end{array}$ & 2 & 0,03 & 0 & 0,00 & 0 & 0,00 & 0 & 0,00 \\
\hline Total & 6.763 & 100 & 6.751 & 100 & 8.368 & 100 & 9.474 & 100 \\
\hline
\end{tabular}
Fonte: RAIS/TEM, elaboração Dieese

A tabela 4 demonstra que, na Rede Municipal de Curitiba, a faixa com maior concentração de trabalhadores é a de 30 a 39 anos de idade. No Brasil, a maior concentração se dá na faixa etária de 35 a 44 anos, seguida pela faixa de 25 a 34 anos. Dado que em Curitiba não se confirma, pois a segunda faixa com maior concentração é a de 40 a 49 anos.

Em Curitiba somadas as faixas etárias, jungindo os de 30 aos de 49 anos, representarão então 68,24\%. Em relação ao perfil brasileiro, a maior concentração está entre profissionais de 25 a 44 anos. Dessa forma, os profissionais do magistério de Curitiba apresentam um faixa etária média mais elevada do que a média nacional.

\section{Tempo de serviço}

Segundo dados do Censo dos Profissionais do Magistério da Educação Básica de 2003, sobre tempo de experiência dos profissionais do magistério no Brasil, conclui-se que mais de $50 \%$ dos 1.524 .878 dos entrevistados estão no magistério há menos de um ano, conforme podemos verificar no gráfico 3:

\section{GRÁFICO 3 - Tempo de experiência dos profissionais do} magistério no Brasil

Fonte: Censo dos profissionais do Magistério no Brasil/2003

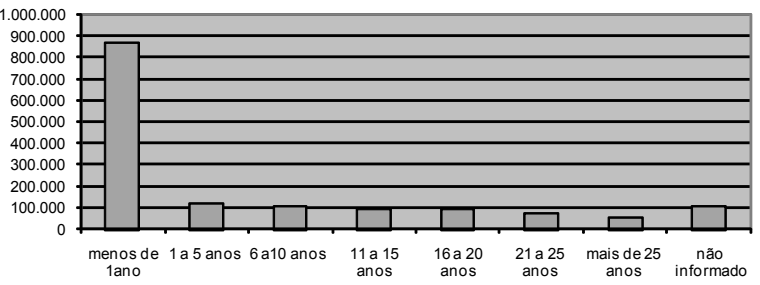

Como será explicitado na tabela 5 , a partir de 2001 ocorre o aumento do percentual dos profissionais que têm menos de quatro anos no magistério. Entretanto, Curitiba difere da média nacional, pois, em 2005, o número de empregos na faixa superior aos 60 meses era de 63,78\% do total. Isso pode estar relacionado também ao fato de que na rede municipal a faixa etária do magistério é mais elevada do que a média nacional.

Tabela 5 - Perfil tempo de emprego - 1999, 2001, 2003 e 2005

\begin{tabular}{|c|c|c|c|c|c|c|c|c|}
\hline \multirow{2}{*}{ 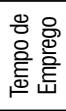 } & \multicolumn{2}{|c|}{1999} & \multicolumn{2}{|c|}{2001} & \multicolumn{2}{|c|}{2003} & \multicolumn{2}{|c|}{2005} \\
\hline & $\begin{array}{c}\text { Empre- } \\
\text { gos }\end{array}$ & Part.\% & \begin{tabular}{|c} 
Empre- \\
gos
\end{tabular} & Part.\% & $\begin{array}{c}\text { Empre- } \\
\text { gos }\end{array}$ & Part.\% & $\begin{array}{c}\text { Empre- } \\
\text { gos }\end{array}$ & Part.\% \\
\hline $\begin{array}{l}\text { Ate 2, } \\
\text { meses }\end{array}$ & 0 & 0,00 & 0 & 0,00 & 202 & 2,41 & 0 & 0,00 \\
\hline $\begin{array}{c}\text { De 3 } \\
\text { a 5 } \\
\end{array}$ & 56 & 0,83 & 2 & 0,03 & 655 & 7,83 & 182 & 1,92 \\
\hline $\begin{array}{c}\text { De } 6,0 \\
\text { a 11 }\end{array}$ & 192 & 2,84 & 39 & 0,58 & 445 & 5,32 & 331 & 3,49 \\
\hline $\begin{array}{l}\text { De } 12 \\
\text { a 23 }\end{array}$ & 0 & 0,00 & 330 & 4,89 & 815 & 9,74 & 788 & 8,32 \\
\hline $\begin{array}{c}\text { De } 24 \\
\text { a } 35\end{array}$ & 10 & 0,15 & 214 & 3,17 & 39 & 0,47 & 1.275 & 13,46 \\
\hline $\begin{array}{c}\text { De } 36 \\
\text { a59 }\end{array}$ & 581 & 8,59 & 10 & 0,15 & 522 & 6,24 & 856 & 9,04 \\
\hline $\begin{array}{l}\text { De } 60 \\
\text { a } 119\end{array}$ & 3.066 & 45,33 & 2.665 & 39,48 & 1.421 & 16,98 & 881 & 9,30 \\
\hline $\begin{array}{c}120 \\
\text { meses } \\
\text { out }\end{array}$ & 2.858 & 42,26 & 3.491 & 51,71 & 4.269 & 51,02 & 5.161 & 54,48 \\
\hline Total & 6.763 & 100,00 & 6.751 & 100,00 & 8.368 & 100,00 & 9.474 & 100,00 \\
\hline
\end{tabular}

A tabela 5 revela, ainda, que, até 1999, aproximadamente $88 \%$ dos profissionais tinham mais de 60 meses de tempo de serviço. A faixa superior a 120 meses mantém uma estabilidade e nela prevalece aproximadamente $50 \%$ do quadro próprio do magistério de 1999 a 2005.

Percebe-se também uma variação em termos percentuais na faixa de tempo de serviço inferior a 59 meses. Em 1999 estavam nessa faixa 12,4\% dos profissionais, em 2001 este número caiu para 6, 24\%, em 2003 teve um aumento considerável para 32,01\%, e em 2005 eram 36,23\% os 
profissionais da rede municipal com menos de 60 meses no exercício do magistério.

Chama à atenção, ainda, a diminuição da participação em termos percentuais dos profissionais na faixa de 60 até 119 meses de 2001 até 2005

Tabela 6: perfil tempo de emprego, 1999, 2001, 2003 e 2005

\begin{tabular}{|c|c|c|c|c|c|c|c|c|}
\hline \multirow{2}{*}{$\begin{array}{c}\text { Tempo } \\
\text { de } \\
\text { Emprego }\end{array}$} & \multicolumn{2}{|c|}{1999} & \multicolumn{2}{|c|}{2001} & \multicolumn{2}{|c|}{2003} & \multicolumn{2}{|c|}{2005} \\
\hline & $\begin{array}{c}\text { Empre- } \\
\text { gos }\end{array}$ & $\begin{array}{l}\text { Part. } \\
(\%)\end{array}$ & $\begin{array}{c}\text { Empre- } \\
\text { gos }\end{array}$ & $\begin{array}{l}\text { Part. } \\
(\%)\end{array}$ & $\begin{array}{l}\text { Empre- } \\
\text { gos }\end{array}$ & $\begin{array}{l}\text { Part. } \\
(\%)\end{array}$ & $\begin{array}{c}\text { Empre- } \\
\text { gos }\end{array}$ & $\begin{array}{l}\text { Part. } \\
(\%)\end{array}$ \\
\hline $\begin{array}{l}\text { Até } 59 \\
\text { meses }\end{array}$ & 839 & 12,4 & 595 & 6,24 & 3.273 & 32,01 & 3.432 & 36,23 \\
\hline $\begin{array}{c}\text { De } 60 \mathrm{a} \\
119\end{array}$ & 3.066 & 45,33 & 2.665 & 39,48 & 1.421 & 16,98 & 881 & 9,30 \\
\hline $\begin{array}{c}120 \\
\text { meses } \\
\text { ou mais }\end{array}$ & 2.858 & 42,26 & 3.491 & 51,71 & 4.269 & 51,02 & 5.161 & 54,48 \\
\hline Total & 6.763 & 100 & 6.751 & 100 & 8.368 & 100 & 9.474 & 100 \\
\hline
\end{tabular}

Isso decorre do fato de a participação em percentual contabilizar o número total de empregos, este era de 6.751 em 2001, saltou para 8.368 em 2003 e para 9.474 em 2005. Dessa forma, foram criados 2.524 novos empregos; isso justifica o aumento considerável de profissionais com menos de cinco anos e a diminuição em termos percentuais dos profissionais na faixa de 60 a 119 meses.

O tempo de serviço dos profissionais do magistério, como critério para a elevação salarial na carreira em Curitiba, foi regulamentado pelo Art. 82 da Lei n. ${ }^{\circ}$ 6761/1985. O integrante do Quadro Próprio do Magistério obterá gratificação por tempo de serviço:

I - Quando do sexo masculino, à base de cinco por cento (5\%) por quinquênio, até completar trinta (30) anos de serviço, num total de trinta por cento $(30 \%)$ e de cinco por centro (5\%) por ano excedente, até atingir o máximo de cinquenta por cento (50\%).

II - Quando do sexo feminino, à base de cinco por cento (5\%) por quinquênio, até completar vinte e cinco anos de serviço, num total de vinte e cinco por cento (25\%), e de cinco por cento (5\%) por ano excedente, até atingir o máximo de cinquenta por cento (50\%).

A valorização do tempo de serviço ou antiguidade é um importante indicador para qualidade na carreira, mas deve estar articulado a outros indicadores, como o pagamento pela maior habilitação, aperfeiçoamento e formação continuada, envolvimento com o projeto político e pedagógico da escola, entre outros.

\section{Remuneração}

Para estabelecer um perfil para a evolução do poder aquisitivo da remuneração do magistério em Curitiba nas últimas décadas, utilizaremos o ano de 1985, pois essa é uma data simbólica para o magistério municipal - foi nesse ano que se deu a aprovação do Estatuto do Magistério. Entretanto, como os anos 1980 e 1990 foram marcados por inflações recordes e desvalorização e arrochos nos salários da maioria das categorias profissionais, será inevitável o uso sistemático de várias tabelas de conversão, vários índices de atualização monetária e, uma idiossincrasia brasileira, várias moedas.

Esse cálculo, por suposto, envolve ferramental e análise acurados, mas, para que tenhamos um parâmetro geral do quadro, podemos considerar estes dados trabalhados pelo DIEESE - que levou em consideração a inflação de cada período, as mudanças de moedas - Cruzeiro, Cruzado, Cruzado Novo, Cruzeiro, Cruzeiro Novo, URV e Real - e a desvalorização real do salário mínimo. ${ }^{6}$

Tabela 7 - Poder aquisitivo do piso salarial dos professores municipais de Curitiba, nov/1985 a jul/2005 (habilitação em nível médio exigida em 1985)

\begin{tabular}{|c|c|c|c|c|c|c|}
\hline \multirow[b]{2}{*}{ Mês / ano } & \multirow[b]{2}{*}{ Moeda } & \multirow[b]{2}{*}{ Piso salarial } & \multicolumn{3}{|c|}{ Salário Mínimo } & \multirow{2}{*}{$\begin{array}{c}\text { Piso } \\
\text { Atualizado } \\
\text { de nov./ } \\
1985 \text { para } \\
\text { nov./ } 2005\end{array}$} \\
\hline & & & Valor & \begin{tabular}{|c|} 
Valor em \\
salários \\
mínimos
\end{tabular} & $\begin{array}{c}\text { Em } \\
\text { set/05 }\end{array}$ & \\
\hline Nov./1985 & $\mathrm{Cr} \$$ & $1.155 .351,00$ & $333.120,00$ & 3,5 & 555,62 & \multirow{4}{*}{$1.927,03$} \\
\hline Jun./2000 & $\mathrm{R} \$$ & 418,27 & 151,00 & 2,8 & 240,73 & \\
\hline Jun./2001 & $\mathrm{R} \$$ & 481,03 & 180,00 & 2,7 & 263,69 & \\
\hline Jun./2005 & $\mathrm{R} \$$ & 563,44 & 300,00 & 1,9 & 300,00 & \\
\hline
\end{tabular}

Um apontamento interessante trazido pelo DIEESE foi em relação ao salário mínimo, convertendo do cruzeiro da época (já que houve outro cruzeiro depois, o cruzeiro do Collor) para o real o salário mínimo. O valor do salário mínimo 
em novembro de 1985 era de Cr\$333.120,00, que convertido para o real de novembro de 2005 correspondia a $\mathrm{R} \$ 555,62$. Porém, o salário vigente para essa época era de apenas $R \$ 300,00$.

Da mesma maneira o inicial da carreira do magistério nesse período, novembro de 1985, era de Cr\$1.155.351,00, que convertido pela mesma fórmula corresponderia, em novembro de 2005 , a $\mathrm{R} \$ 1.927,03$, porém, o município garantia em novembro de 2005 um piso salarial para o magistério de apenas $R \$ 563,44$. É notório que poder de compra do salário dos professores de Curitiba teve considerável desvalorização no período analisado.

O salário inicial utilizado na tabela se referia a professores com formação em magistério - nível médio. Com a aprovação do Plano de Cargos, Carreira e Salários em 2001 em Curitiba, foi exigida como condição de ingresso o curso superior. Assim, um acréscimo de quinze por cento foi atribuído aos profissionais que, mesmo em estágio probatório, apresentavam a titulação em cursos de graduação.

Na sequência, outra avaliação da remuneração será realizada utilizando como referência de análise a RAIS do Ministério do Trabalho, que diz respeito ao valor nominal do salário a partir da instituição do PCCS. A média salarial que resulta da RAIS/ MTE de 1999 a 2005 demonstra que em termos nominais ocorreu uma valorização dos salários.

Tabela 8 - Média salarial dos profissionais do magistério baseada em salários mínimos vigentes em cada época analisada

\begin{tabular}{|c|c|c|c|c|c|c|c|c|}
\hline \multirow{2}{*}{ 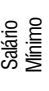 } & \multicolumn{2}{|c|}{1999} & \multicolumn{2}{|c|}{2001} & \multicolumn{2}{|c|}{2003} & \multicolumn{2}{|c|}{2005} \\
\hline & $\begin{array}{c}\text { Empre- } \\
\text { gos }\end{array}$ & $\begin{array}{c}\text { Sal. } \\
\text { Médio }\end{array}$ & $\begin{array}{c}\text { Empre- } \\
\text { gos }\end{array}$ & $\begin{array}{l}\text { Sal. } \\
\text { Médio }\end{array}$ & $\begin{array}{c}\text { Empre- } \\
\text { gos }\end{array}$ & $\begin{array}{c}\text { Sal. } \\
\text { Médio }\end{array}$ & $\begin{array}{c}\text { Empre- } \\
\text { gos }\end{array}$ & $\begin{array}{c}\text { Sal. } \\
\text { Médio }\end{array}$ \\
\hline 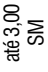 & 65 & 367,30 & 66 & 462,54 & 1.529 & 684,20 & 1.479 & 843,00 \\
\hline 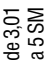 & 2.482 & 570,23 & 2.773 & 679,17 & 3.586 & 878,11 & 3.851 & $1.148,73$ \\
\hline 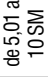 & 2.929 & $1.033,03$ & 2.916 & $1.280,16$ & 2.555 & $1.616,63$ & 3.118 & $2.026,30$ \\
\hline 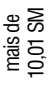 & 1.251 & $2.069,14$ & 894 & $2.641,75$ & 669 & $3.417,55$ & 759 & $4.258,13$ \\
\hline 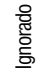 & 36 & 0,00 & 102 & 0,00 & 29 & 0,00 & 267 & 0,00 \\
\hline 䜵 & 6.763 & $1.042,89$ & 6.751 & $1.186,27$ & 8.368 & $1.267,82$ & 9.474 & $1.596,00$ \\
\hline
\end{tabular}

Fonte: RAIS/MTE, elaboração Dieese
A tabela que apresenta a média salarial no período estudado revela que em 2005 a faixa de empregos com vencimento entre três e cinco salários mínimos manteve-se estável, com aumento significativo em 2005 da faixa de empregos com vencimento de até três salários mínimos (15,61\%), enquanto, nessa mesma faixa, em 1999 estavam 0,96\% de empregos. Também a faixa de empregos com vencimento superior ao índice de 10 salários mínimos decaiu significativamente após 1999, representando em 2005 somente 8,01\% dos empregos do quadro próprio do magistério que estão na ativa.

Em abril de 2007 o vencimento inicial dos profissionais do magistério com graduação para 20 horas de trabalho era de $\mathrm{R} \$ 721,00$ para profissionais com graduação. E no mês de maio de 2008, o vencimento inicial passou para $R \$ 902,00$, isso porque ocorreu, além dos reajustes inflacionários respectivos do período, a incorporação de 60\% dos $31,71 \%$ do que seria a diferença entre as áreas de atuação, que será extinta em 2010.

\section{Enquadramento na Carreira}

Em 2001 foi criado o Plano de Carreira para os profissionais do magistério em Curitiba; ${ }^{7}$ entretanto, devido à organização e aos processos reivindicatórios dos trabalhadores, ocorreram mudanças significativas na lei. Dessa forma, defesas históricas dos trabalhadores como o pagamento por maior habilitação conquistado pelo magistério em 1985 com o Estatuto Azul (Lei n. $\left.{ }^{\circ} 6761 / 85 i\right)$ depois perdida com a Reforma administrativa (Lei n. ${ }^{\circ}$ 7670/91) na gestão de Jaime Lerner, e reconquistada no novo enquadramento por força da Lei n. ${ }^{\circ}$ 12.348/2007.

Assim, no caso de Curitiba, o plano de carreira, por um lado, estimulou a formação dos profissionais do magistério e, por outro, se transformou num fator de agregação dos trabalhadores na luta por ampliação de direitos.

A tabela salarial, apresentada a seguir, sofreu em agosto de 2007 alterações significativas. Para adequar-se às alterações, ela adquiriu a seguinte estrutura:

7 Para compreensão das diversas legislações e alterações na carreira docente em Curitiba, ver: ABREU. D. C. Carreira e perfil do profissional do magistério na Rede Municipal de Ensino de Curitiba: História e impacto da política brasileira de valorização do magistério. Curitiba, 2008. 169f. Dissertação (Mestrado em Educação). Universidade Federal do Paraná, Curitiba, 2008. 


\begin{tabular}{|c|c|c|c|c|c|c|c|c|c|c|c|c|}
\hline & & \multicolumn{2}{|c|}{ PADRÓES } & A & B & C & D & $\mathbf{E}$ & $F$ & G & $\mathbf{H}$ & I \\
\hline & Parte Especial & $\begin{array}{l}500^{*} \\
501^{*} \\
502^{*} \\
\end{array}$ & $\begin{array}{l}100^{\star \hbar} \\
101^{\star \star} \\
102^{k \hbar}\end{array}$ & $\begin{array}{r}664,72 \\
852,27 \\
1.092,71 \\
\end{array}$ & $\begin{array}{r}683,31 \\
876,11 \\
1.123,34 \\
\end{array}$ & $\begin{array}{r}702,44 \\
900,67 \\
1.154,77 \\
\end{array}$ & $\begin{array}{r}722,11 \\
925,88 \\
1.187,09 \\
\end{array}$ & $\begin{array}{r}742,33 \\
951,81 \\
1.220,37 \\
\end{array}$ & $\begin{array}{r}763,13 \\
978,44 \\
1.254,54 \\
\end{array}$ & $\begin{array}{r}\mathbf{7 8 4 , 5} \\
1.005,83 \\
1.289,65 \\
\end{array}$ & $\begin{array}{r}\mathbf{8 0 6 , 4 5} \\
1.034,02 \\
1.325,74 \\
\end{array}$ & $\begin{array}{r}829,03 \\
1.062,98 \\
1.362,91 \\
\end{array}$ \\
\hline \multirow{4}{*}{ 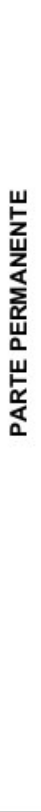 } & $\begin{array}{c}\text { NIVEL I } \\
\text { Graduação }\end{array}$ & $\begin{array}{l}503^{\star} \\
\mathbf{5 0 4}^{\star} \\
505^{\star} \\
\mathbf{5 0 6}^{\star} \\
507^{\star} \\
\mathbf{5 0 8}^{\star}\end{array}$ & $\begin{array}{l}103^{\star \star} \\
104^{\star \star} \\
105^{\star \star} \\
106^{\star \star}\end{array}$ & $\begin{array}{r}980,11 \\
1.256,65 \\
1.611,22 \\
2.065,84 \\
2.648,71\end{array}$ & $\begin{array}{l}1.007,54 \\
1.291,84 \\
1.656,33 \\
2.123,68 \\
\mathbf{2 . 7 2 2 , 8 7}\end{array}$ & $\begin{array}{l}1.035,78 \\
1.328,03 \\
1.702,73 \\
2.183,14 \\
2.799,11\end{array}$ & $\begin{array}{r}830,45 \\
1.064,76 \\
1.365,17 \\
1.750,40 \\
2.244,27 \\
2.877,49 \\
\end{array}$ & $\begin{array}{r}853,7 \\
1.094,58 \\
1.403,41 \\
1.799,40 \\
2.307,11 \\
2.958,06 \\
\end{array}$ & $\begin{array}{r}877,61 \\
1.125,22 \\
1.442,71 \\
1.849,76 \\
2.371,71 \\
3.040,88 \\
\end{array}$ & $\begin{array}{r}902,17 \\
1.156,74 \\
1.483,11 \\
1.901,60 \\
2.438,12 \\
3.126,03\end{array}$ & $\begin{array}{r}927,45 \\
1.189,14 \\
1.524,66 \\
1.954,84 \\
2.506,39 \\
3.213,56 \\
\end{array}$ & $\begin{array}{r}953,42 \\
1.222,43 \\
1.567,34 \\
2.009,57 \\
2.576,56 \\
3.303,54 \\
\end{array}$ \\
\hline & $\begin{array}{c}\text { NIVEL II } \\
\text { Especialização }\end{array}$ & $\begin{array}{l}512^{\star} \\
\mathbf{5 1 3}^{\star} \\
514^{\star} \\
\mathbf{5 1 5}^{\star} \\
516^{\star} \\
\mathbf{5 1 7}^{\star}\end{array}$ & $\begin{array}{l}107^{\star \star \star} \\
108^{\star \star} \\
109^{\star \star \star} \\
110^{\star \star}\end{array}$ & $\begin{array}{r}879,08 \\
1.127,12 \\
1.445,16 \\
1.852,92 \\
2.375,71 \\
3.046,01 \\
\end{array}$ & $\begin{array}{r}903,68 \\
1.158,68 \\
1.485,64 \\
1.904,79 \\
2.442,23 \\
3.131,30 \\
\end{array}$ & $\begin{array}{r}929,01 \\
1.191,13 \\
1.527,21 \\
1.958,15 \\
2.510,62 \\
3.218,98 \\
\end{array}$ & $\begin{array}{r}955,02 \\
1.224,46 \\
1.569,97 \\
2.012,95 \\
2.580,91 \\
3.309,11 \\
\end{array}$ & $\begin{array}{r}981,76 \\
1.258,76 \\
1.613,96 \\
2.069,33 \\
2.653,18 \\
3.401,77 \\
\end{array}$ & $\begin{array}{l}1.009,24 \\
1.294,01 \\
1.659,14 \\
2.127,27 \\
2.727,47 \\
3.497,02 \\
\end{array}$ & $\begin{array}{l}1.037,50 \\
1.330,27 \\
1.705,60 \\
2.186,84 \\
2.803,84 \\
3.594,93 \\
\end{array}$ & $\begin{array}{l}1.066,57 \\
1.367,50 \\
1.753,35 \\
\mathbf{2 . 2 4 8 , 0 6} \\
2.882,34 \\
\mathbf{3 . 6 9 5 , 5 9} \\
\end{array}$ & $\begin{array}{l}1.096,41 \\
1.405,78 \\
1.802,43 \\
\mathbf{2 . 3 1 1 , 0 0} \\
2.963,05 \\
\mathbf{3 . 7 9 9 , 0 7} \\
\end{array}$ \\
\hline & $\begin{array}{l}\text { NiVEL III } \\
\text { Mestrado }\end{array}$ & $\begin{array}{l}520^{\star} \\
521^{\star} \\
522^{\star} \\
523^{\star} \\
524^{\star} \\
525^{\star} \\
\end{array}$ & $\begin{array}{l}111^{\star \star} \\
112^{\star \star} \\
113^{\star \star} \\
114^{\star \star}\end{array}$ & $\begin{array}{l}1.010,94 \\
\mathbf{1 . 2 9 6 , 2 1} \\
1.661,93 \\
\mathbf{2 . 1 3 0 , 8 7} \\
2.732,07 \\
\mathbf{3 . 5 0 2 , 9 2} \\
\end{array}$ & $\begin{array}{l}1.039,25 \\
1.332,49 \\
1.708,49 \\
2.190,50 \\
2.808,57 \\
3.601,00 \\
\end{array}$ & $\begin{array}{l}1.068,35 \\
1.369,81 \\
1.756,31 \\
2.251,87 \\
2.887,21 \\
3.701,83 \\
\end{array}$ & $\begin{array}{l}1.098,26 \\
1.408,15 \\
1.805,49 \\
2.314,91 \\
2.968,05 \\
3.805,48 \\
\end{array}$ & $\begin{array}{l}1.129,03 \\
1.447,59 \\
1.856,05 \\
2.379,74 \\
3.051,15 \\
3.912,03 \\
\end{array}$ & $\begin{array}{l}1.160,65 \\
1.488,11 \\
1.908,01 \\
2.446,35 \\
3.136,59 \\
4.021,57 \\
\end{array}$ & $\begin{array}{l}1.193,11 \\
1.529,78 \\
1.961,42 \\
2.514,86 \\
3.224,41 \\
4.134,17 \\
\end{array}$ & $\begin{array}{l}1.226,55 \\
1.572,63 \\
2.016,37 \\
2.585,29 \\
3.314,69 \\
4.249,93 \\
\end{array}$ & $\begin{array}{l}1.260,90 \\
1.616,67 \\
2.072,82 \\
2.657,67 \\
3.407,51 \\
4.368,93 \\
\end{array}$ \\
\hline & $\begin{array}{c}\text { NIVEL IV } \\
\text { Doutorado }\end{array}$ & $\begin{array}{l}528^{*} \\
529^{*} \\
530^{*} \\
531^{*} \\
532^{*} \\
533^{*}\end{array}$ & & $\begin{array}{l}1.162,58 \\
1.490,61 \\
1.911,18 \\
2.450,41 \\
3.141,79 \\
4.028,23\end{array}$ & $\begin{array}{l}1.195,14 \\
1.532,34 \\
1.964,69 \\
2.519,02 \\
3.229,76 \\
4.141,03\end{array}$ & $\begin{array}{l}1.228,60 \\
1.575,25 \\
2.019,70 \\
2.589,55 \\
3.320,19 \\
4.256,97\end{array}$ & $\begin{array}{l}1.263,00 \\
1.619,35 \\
2.076,25 \\
2.662,06 \\
3.413,16 \\
4.376,17\end{array}$ & $\begin{array}{l}1.298,37 \\
1.664,70 \\
2.134,39 \\
2.736,60 \\
3.508,72 \\
4.498,70\end{array}$ & $\begin{array}{l}1.334,72 \\
1.711,31 \\
2.194,15 \\
2.813,22 \\
3.606,97 \\
4.624,67\end{array}$ & $\begin{array}{l}1.372,09 \\
1.759,22 \\
2.255,59 \\
2.891,99 \\
3.707,96 \\
4.754,16\end{array}$ & $\begin{array}{l}1.410,51 \\
1.808,48 \\
2.318,74 \\
2.972,97 \\
3.811,79 \\
4.887,27\end{array}$ & $\begin{array}{l}1.450,01 \\
1.859,12 \\
2.383,67 \\
3.056,21 \\
3.918,52 \\
\mathbf{5 . 0 2 4 , 1 2}\end{array}$ \\
\hline
\end{tabular}

Fonte: Secretaria de Recursos Humanos

Os padrões 500 a 523, criados por força da Lei n. ${ }^{\circ} 12.348$, passarão a vigorar após o término do reenquadramento de todos os profissionais da docência I, que ocorre em 2010. Já os padrões, da terceira coluna da tabela, 100 a 123 continuam vigorando até 2010, quando ocorre a equiparação. Foi necessária a mudança já que duas linhas foram criadas em cada nível em 2007.

As progressões na carreira em Curitiba ocorrem de forma vertical e horizontal. O avanço vertical contempla a titulação acadêmica, e a horizontal considera basicamente a formação continuada.

O nível (expresso na vertical) explicita a posição do Profissional do Magistério na Carreira segundo o grau de habilitação. Já o Padrão (expresso na terceira e quarta coluna na vertical) caracteriza a faixa de vencimentos que por sua vez é composta por nove referências (na horizontal). Para progredir de um padrão para outro (exemplo do padrão 103 para o 104), o profissional deverá avançar todas as referências do padrão 103 de $A$ até a $H$, assim na próxima progressão ele passará para o padrão 104 referência A. Dessa forma, a Referência é a posição distinta na faixa de vencimentos de cada padrão que corresponde à posição de um ocupante de um cargo na tabela salarial.

Sobre o atual enquadramento na carreira, ${ }^{8}$ no ano de 2009, o inicial passará a ser o 504 A, e no ano de 2010 o mesmo se estabiliza no que é hoje o Padrão 504 C, passando a ser a posição para todos que ingressarem na carreira, independente da área de atuação.

A Secretaria de Recursos Humanos em abril de 2008 divulgou uma demonstração da situação funcional, do nível, do padrão e da referência de cada profissional do magistério segundo o enquadramento na carreira (ABREU, 2008); em síntese, temos o seguinte:

80 reenquadramento na carreira que ocorreu por força da Lei $n .^{\circ} 12.348 / 2007$. Primeiro porque este processo tem o objetivo de, em 2010, eliminar a diferença entre as áreas de atuação docência I e docência II, mantendo assim o mesmo valor inicial de salário para os profissionais com formação em nível superior, independendo da área de atuação. Dessa forma, gradativamente as 10 primeiras referências do plano serão eliminadas, garantido que em 2010 o inicial seja o padrão 503 Referência C. Na tabela acima se observa que no padrão 503, as referências $A$ a $C$ não mencionam os valores dos vencimentos, isso porque a partir de agosto de 2007 o inicial da carreira passou a ser o Padrão 503 e Referência D, e no mês de maio de 2008 o vencimento inicial da carreira do magistério passou a ser o Padrão 503 e Referência G. 
Tabela 9 - Enquadramento na carreira de profissionais do magistério/2008

\begin{tabular}{|c|c|c|c|}
\hline Níveis da carreira & Aposentados & $\begin{array}{c}\text { Efetivo } \\
\text { Exercício }\end{array}$ & Total \\
\hline Parte especial & 362 & 519 & 881 \\
\hline Nível I graduação & 1.477 & 6.583 & 8.058 \\
\hline $\begin{array}{l}\text { Nível II especialização } \\
\text { Latu sensu }\end{array}$ & 464 & 3.498 & 3.960 \\
\hline Nível III Mestrado & 12 & 59 & 71 \\
\hline $\begin{array}{l}\text { Nível IV Doutorado } \\
\text { (Esse nivel foi criado pela Lei } \\
\text { n. } 12.348 / 2007 \text {; antes os } \\
\text { profissionais com doutorado } \\
\text { ficavam estagnados no nível III) }\end{array}$ & 0 & 0 & 0 \\
\hline Total & 2.315 & 10.660 & 12.975 \\
\hline
\end{tabular}

Observando a parte especial do plano, em que estão enquadrados os profissionais em efetivo exercício, observa-se que 519 possuem a escolaridade mínima para o exercício da função, ou seja, ensino médio na modalidade normal. Esta condição, como condição de ingresso, foi extinta pela Lei n. ${ }^{\circ} 10.190 / 2001$, assim, este quadro é chamado de parte especial porque nele estão os

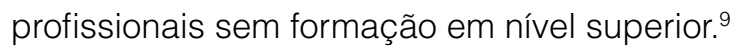

A média salarial desse grupo que se encontra na parte especial é inferior ao valor inicial da carreira, que em maio de 2008 foi de $\mathrm{R} \$ 902,17$. Um estímulo para esses trabalhadores é que ao fazer a transposição para a parte permanente do plano terão um acréscimo de $15 \%$ estabelecido desde o PCCS de 2001, resultante da diferença entre a parte especial e a parte permanente do plano. E também a garantia de mais 10 referências (2,8\% de reajuste cada). Portanto, serão mais de $45 \%$ de acréscimo na remuneração.

Um dado interessante quando se analisa o nível I da parte permanente, é que, na primeira referência da tabela salarial, encontramos 3.293 professores com menos de cinco anos, isso explica a mudança de perfil em relação ao tempo de serviço, na rede municipal. Como em 2005 foi realizado concurso externo para profissionais do magistério na disciplina de educação física e estes ingressaram no padrão 504 e Referência B, e em agosto de 2007 receberam como premiação ${ }^{10}$, por ocasião da Lei n. ${ }^{\circ}$ 12.348, mais uma referência, estão atualmente no 504 C (são 528 profissionais) esta é outra referência que concentra profissionais com menos de cinco anos na rede municipal.

Portanto, de um total de 6.584 empregos no nível I, a metade acaba de ingressar na carreira do magistério. Importa considerar que a administração municipal estabelece um número de vagas anuais para que os profissionais possam migrar do nível I para o nível II. Este procedimento, que é chamado de crescimento vertical, vem ocorrendo a cada ano, entretanto a Lei n. ${ }^{\circ} 10.190 / 2001$, que instituiu o plano de carreira, não estabelece a periodicidade e quanto ao número de vagas, disciplina 100 por procedimento.

Como explicitado na tabela 11, em abril de 2008, estavam enquadrados no nível II da carreira 3.498 profissionais habilitados em pós-graduação Latu Sensu (360 horas de carga horária). Vale ressaltar que a partir de 2006 passaram a ser garantidas 800 vagas/ano para a elevação do nível I para o nível II. Quando considerado o número de profissionais que ainda estão no nível I do plano, ou seja, com a graduação, o enquadramento de todos os profissionais só ocorrerá em oito anos. Dessa forma, muitos trabalharão com a habilitação, sem receber por ela. Situação que pode ser resolvida à medida que o plano de carreira reconheça a remuneração de acordo com o nível de habilitação de forma automática e a qualquer tempo.

Voltando ao plano de carreira do magistério público de Curitiba, pode-se observar que até

9 Há casos de professores com habilitação em outras áreas do conhecimento, que não habilitam para a licenciatura, como sugere a legislação nacional eles podem tanto fazer uma licenciatura quanto uma complementação pedagógica, para migrarem à parte permanente do plano.

10 Conforme o parecer da assessoria jurídica do Sismmac, na Lei Municipal $n .^{\circ}$ 12348/2007 foram concedidas duas referências como premiação para os ocupantes da área de atuação Docência II. Sobre as verbas recebidas a título de qualidade e produtividade não incide contribuição previdenciária e, portanto, não são incorporáveis aos proventos de aposentadoria dos servidores públicos. As premiações concedidas nos planos de carreira não atingem os aposentados, mesmo que tenham o direito à paridade constitucional. Ao pagar remunerações variáveis sem incidência de contribuição previdência desobriga-se o Município do pagamento de sua parte de $22 \%$ para o regime de previdência. Pelo mesmo motivo, o valor das aposentadorias são menores, portanto, os servidores demorarão mais para se aposentar e o Município gastará menos com aposentados. 
abril estavam enquadrados no nível III, em que a titulação exigida é o mestrado, 59 professores em efetivo exercício e 12 aposentados. A Secretaria Municipal de Educação de Curitiba tem garantido aos profissionais que são aprovados em programas de mestrado licença para estudo com manutenção dos vencimentos, o que caracteriza um importante estímulo para o aperfeiçoamento profissional. ${ }^{11}$

O Nível IV, que exige a titulação de doutorado, foi criado pela Lei n. ${ }^{\circ}$ 12.348/2007, e ainda não ocorreu enquadramento na carreira nesse nível, o que deveria ocorrer no segundo semestre de 2008. É importante destacar que a previsão é de que os profissionais com doutorado sejam enquadrados automaticamente no próximo crescimento vertical, no segundo semestre de 2008.

\section{Jornada de trabalho, dedicação exclusiva e hora-atividade}

Nas discussões sobre a jornada ideal para os profissionais da educação, não há consensos, e dessa forma, nacionalmente, temos jornadas variadas, com tempo de hora-atividade - aquela destinada ao estudo e planejamento - também diverso. Uma jornada de trabalho que permita ao profissional do magistério melhores condições de trabalho, tempo para formação continuada e planejamento das atividades e lazer são condições mínimas de qualidade na carreira docente, bem como, e principalmente, de qualidade na educação, direito do aluno, razão única da existência da escola.

Em Curitiba os vínculos dos profissionais do magistério são de 20 horas semanais com 20\% de hora atividade em regime estatutário. Na prática, como se verá, esses vínculos facilitam a dobra de jornada. Valendo-se desse argumento a CNTE defende uma jornada de 30 horas semanais com $30 \%$ de hora atividade, o que, para esta entidade, pode se traduzir num indicador de qualidade na carreira à medida que impossibilita a dobra de jornada. Entretanto, como se pode deduzir ao observar outras categorias profissionais, como médicos, enfermeiros etc., há profissionais que têm jornada dupla de 30 horas.

Hoje a legislação trabalhista brasileira garante uma jornada máxima de 44 horas para os trabalhadores em geral, e, no momento, as centrais sindicais estão numa campanha de redução da jornada para 40 horas semanais; diante disso, é difícil fazer com que a luta, seja ela por 20 ou 30 horas semanais, dos trabalhadores em educação tenha legitimidade perante a sociedade.

Não há, por outro lado, como ser ingênuo e desconsiderar que vivemos em uma sociedade de consumo, na qual, é imperativo, todos são compelidos a comprar, a consumir os novos produtos e serviços que o mercado ensandecido está cada vez mais e mais ávido por vender. Nesse sentido, seria ainda mais ingênuo estabelecer um salário ou um padrão de vida ideais, a partir dos quais os profissionais da educação, que são cidadãos submetidos à mesma lógica e apelos consumistas, estivessem desmotivados a realizar a dobra de jornada.

Em 2005 por ocasião da realização da Prova Brasil, $^{12}$ a Secretaria Municipal de Educação publicou um caderno ${ }^{13}$ no qual apresentou dados de alguns professores da RME. O documento apresentava um perfil dos profissionais do

11 Até 2008 os profissionais que se ausentavam da RME para realizar seus estudos em mestrado ou doutorado na área de educação, na volta à rede deveriam permanecer quantidade igual de tempo, sem nenhum avanço salarial. Como as licenças nos últimos quatro anos foram concedidas a muitos profissionais, pode ser que muitos, devido ao critério excludente descrito anteriormente, tenham mestrado e ainda não tenham alçado o nível III. Na negociação salarial de 2008, foi acordado entre o Sismmac e a SME que para os próximos procedimentos de crescimento vertical esse critério deixará de existir. $E$ os profissionais ao retornarem para a rede municipal após a licença remunerada para estudos, preenchendo os demais requisitos, poderão avançar na carreira.

12 A Prova Brasil foi idealizada para produzir informações sobre o ensino oferecido por município e escola, individualmente, com o objetivo de auxiliar os governantes nas decisões e no direcionamento de recursos técnicos e financeiros, assim como a comunidade escolar no estabelecimento de metas e implantação de ações pedagógicas e administrativas, visando à melhoria da qualidade do ensino. Como avaliação que compõe o Sistema Nacional de Avaliação da Educação Básica (Saeb), a Prova Brasil é desenvolvida e realizada pelo Instituto Nacional de Estudos e Pesquisas Educacionais Anísio Teixeira (Inep), autarquia do Ministério da Educação (MEC).

13 No site, cidadedoconhecimento.org.br, a publicação está disponível com o título Caracterização das escolas da rede municipal de ensino - Prova Brasil Curitiba. 
magistério regentes das turmas que realizaram a prova e dos aplicadores que também faziam parte do quadro do magistério. O número de participantes representava $27 \%$ dos profissionais do magistério da rede no período. Naquela ocasião, quanto à jornada de trabalho, somente 15\% afirmaram trabalhar 40 horas semanais na prefeitura.

Já em 2008, a distribuição dos profissionais do magistério, de acordo com o número de vínculos no serviço público municipal, estava assim distribuído:

\section{Tabela 10 - Perfil da jornada de trabalho na RME}

\begin{tabular}{|c|c|c|}
\hline $\begin{array}{c}\text { Matrículas no magistério } \\
\text { em 2008 na RME de } \\
\text { Curitiba - Dados oficiais }\end{array}$ & $\begin{array}{c}\text { Número de } \\
\text { Vínculos }\end{array}$ & $\begin{array}{c}\text { Jornada de horas } \\
\text { semanais na } \\
\text { PMC }\end{array}$ \\
\hline 10.836 & 1 & 20 horas \\
\hline 2.139 & 2 & 40 horas \\
\hline
\end{tabular}

Fonte: PMC/SMRH

\section{GRÁFICO 4 - Perfil da jornada de trabalho na RME}

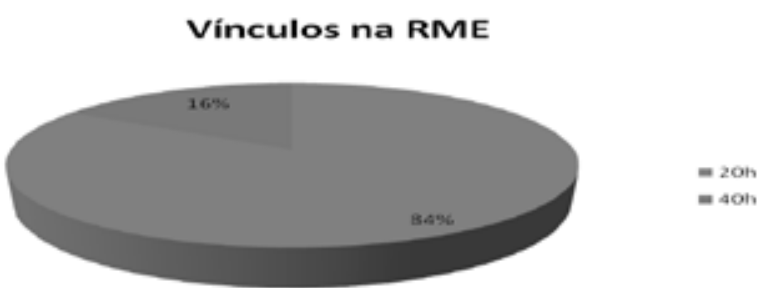

Na análise da tabela 12, conclui-se que entre os profissionais em efetivo exercício e aposentados, que integralizam 12.975, somente 2.139 possuem dois padrões, ou seja, são concursados em dois cargos de 20 horas na rede municipal.

\section{A dobra dentro da RME}

Em 2008, a Secretaria Municipal de Recursos Humanos informou ao SISMMAC em mesa de negociação que o número de profissionais do magistério que estavam realizando a dobra de jornada se mantinha em torno de 1.200. Este número não é fixo por vários motivos, mas principalmente porque essas dobras são geralmente contratadas para suprir substituições temporárias. Na RME, a dobra é feita pelo Regime Integral de Trabalho, o RIT, e não é reconhecida como hora extra, dessa forma o profissional tem somente seu vencimento base dobrado.

Como essa é a realidade efetiva, o quadro que se apresentou acima atende apenas pró-forma aos dados oficiais. Refazendo o quadro com o que realmente ocorre no dia a dia da RME, este fica assim configurado:
QUADRO 1 - Matrículas e dobras no magistério em 2008 na RME de Curitiba

\begin{tabular}{|c|c|c|}
\hline Empregos & $\begin{array}{c}\text { Número de } \\
\text { Vínculos }\end{array}$ & $\begin{array}{c}\text { Jornada de horas } \\
\text { semanais na PMC }\end{array}$ \\
\hline 8.436 & 1 & 20 horas \\
\hline 3.339 & 2 & 40 horas \\
\hline
\end{tabular}

Fonte: Dados oficiosos SMRH e SME

\section{GRÁFICO 5 - Matrículas e dobras no magistério em 2008} Vínculos e dobras na RME

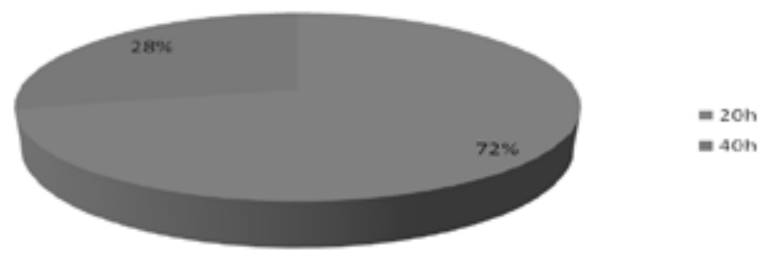

É provável que muitos profissionais do magistério da RME tenham outro padrão em redes de outros municípios da região metropolitana de Curitiba com mais uma jornada de 20 horas. Outra possibilidade é um outro vínculo na rede estadual, já que nesta a carga horária também é de 20 horas/aula na semana.

A condição de Curitiba parece ser confortável, já que $72 \%$ dos profissionais do quadro não fazem a dobra de jornada na própria RME. Entretanto, esta é mais uma situação em que os dados estatísticos escondem grande parte da realidade, pois não há a dobra no município, mas outros cenários se instituem, pois os vínculos de 20 horas permitem jornadas triplas de trabalho, podendo um mesmo profissional realizar uma carga horária semanal de 60 horas.

Para os profissionais com dois padrões concursados na RME de Curitiba, a terceira jornada, muitas vezes, é também uma realidade, já que não há como evitar que este cumpra mais 20 horas em uma rede privada. Essa realidade, sabemos, é, antes de tudo, fruto da desvalorização do magistério, e ao profissional, nas mais das vezes, não sobrou alternativa senão essa jornada desumana. Porém, a grande vítima desta realidade é a qualidade da educação, é dizer, o aluno.

Uma idéia prática para evitar essa situação seria instituir que todos os vínculos sejam de 40 horas, assim a dobra estaria inviabilizada na rede pública e na rede privada. Claro que um profissional que eventualmente quisesse trabalhar apenas 20 horas, neste caso, seria prejudicado, mas sabemos que 
esta situação ou não ocorre ou é exceção extrema. Atualmente o acúmulo de vínculos, apesar de encontrar na legislação nacional restrições e impedimentos, ocorre quase como regra, pois são possíveis, mesmo que ilegais, tanto em redes públicas quanto em redes privadas.

Outra questão que vem à tona é que a dedicação exclusiva dos profissionais a uma mesma rede ou mesmo a uma mesma escola é importante também para a qualidade na educação, já que assim pode haver melhores condições para o envolvimento dos profissionais no projeto pedagógico da escola. Nesse sentido, a Resolução n. ${ }^{\circ}$ 03/CNE apontava para incrementos salariais aos profissionais que tivessem dedicação exclusiva.

Segundo o EDUCACENSO/2007 - um sistema de cadastro on-line INEP/MEC que visa manter um cadastro único em uma base de dados centralizada de escolas, docentes, auxiliares de educação infantil e alunos -, dois de cada dez professores trabalham em mais de uma escola e $36 \%$ deles dão aula em mais de um turno.

Pelo menos no caso de Curitiba há um agravante. Se considerados os horários de término das aulas do período da manhã e início do período da tarde, em média, esse intervalo não passa de uma hora nas escolas da rede municipal. Portanto, um profissional do magistério que trabalhe em unidades diferentes terá que, nesse curto intervalo, realizar o seu deslocamento de uma unidade para outra e ainda realizar uma refeição.

Ao discutirmos jornada e dedicação exclusiva do magistério público, outra questão não menos importante para a qualidade da educação e da carreira dos profissionais é o tempo de dedicação remunerado fora da sala de aula, comumente chamado de hora-atividade, ou no caso da rede municipal de Curitiba de hora-permanência.

Quanto a esse período reservado para hora atividade, a Lei n. ${ }^{\circ}$ 9.394/1996, no Art. 67, estabeleceu que os sistemas de ensino, com o objetivo da valorização dos profissionais da educação, deveriam assegurar período reservado a estudos, planejamento e avaliação, incluído na carga horária de trabalho. Mas a lei é omissa em relação à proporção da jornada que deveria ser reservada para esse fim.
O trabalho do professor não é estanque nem fragmentado; a sociedade, as legislações e as formas de gestão exigem do profissional maior envolvimento com a comunidade, com o projeto pedagógico da escola. Além de tempo para preparar as aulas e corrigir as provas, o professor necessita dispor de tempo para a integração com os alunos. Por isso, precisa ter tempo, e esse tempo precisa ser remunerado, para além das horas aulas:

0 trabalho do professor não se restringe ao exercício da sua função dentro da sala de aula, implica em atualização e preparação constantes para que seja realizado a contento. Muitas tarefas não são realizadas na presença dos alunos e demandam atenção em outros momentos. Assim sendo, muitas turmas, turmas em escolas diferentes, alunos em níveis diferentes de ensino, turmas do noturno e diurno implicam em preparação de esquemas diferentes de aulas adaptados a cada realidade. Isso implica em maior volume de trabalho, tanto no que se refere a mais horas de dedicação, como em maior esforço intelectual. (SORANTO; PINTO, 1999, p. 289).

A Resolução n. ${ }^{\circ} 03$ do Conselho Nacional de educação de outubro de 1987 fixou as diretrizes nacionais para carreira e remuneração do magistério, e no Art. 6 inciso IV estabeleceu que a jornada de trabalho pode ser de até 40 horas semanais e destas, 20\% a 25\% devem ser em horas-atividade. O problema é que, além de fixar um percentual limitado, quando o defendido, por exemplo, pela CNTE já era 30\%, diminui alguns índices de hora-atividade que já vigoravam no país. Elemento negativo à medida que a valorização da carreira está relacionada à ampliação do percentual de hora-atividade destinado às horasatividade dos profissionais do magistério.

Em Curitiba a Resolução n. 03 do CNE não interferiu na constituição da jornada de horapermanência. Aqui, 20\% da jornada é destinada à hora-atividade, direito garantido pelo Estatuto do Magistério desde 1985. A hora-permanência na Rede Municipal de Ensino está concentrada em um dia da semana. Assim, das 20 horas semanais, os profissionais do magistério têm quatro horas para estudo e planejamento.

\section{Considerações Finais}

Nesse trabalho com o com o auxílio da Rais/TME e de dados fornecidos pela Prefeitura de Curitiba, 
por meio das secretarias de Recursos Humanos e da Secretaria Municipal de Educação, buscou-se definir um perfil do magistério na rede municipal.

Desse perfil, que tem base em dados da RAIS/TEM, que considerou o intervalo de 1999 a 2005, e informações obtidas pelo SISMMAC junto à Secretaria de Educação e de Recursos Humanos, destaca-se que $97,31 \%$ do quadro do magistério é composto por mulheres, e que mesmo nesta rede, em que a participação masculina é ínfima, os vencimentos dos homens são superiores. Com relação à escolaridade, constatou-se que $82,58 \%$ do quadro do magistério possuía curso superior. E ainda com relação à faixa etária, Curitiba está acima da média nacional, e a faixa de maior concentração de profissionais se dá entre os 30 e 39 anos. Quanto ao tempo de serviço, a média daqueles com mais de 120 meses está acima de 54\%. Vale dizer que devido à ampliação do número de empregos, aumentou a porcentagem (36,23\%) dos profissionais com menos de 60 meses.
Desde a provação do plano de Carreira, Lei n. ${ }^{\circ}$ 10.190/2001, no decorrer dos anos ele foi sofrendo alterações. Em 2007 o magistério voltou a ter seu pagamento pautado pela maior habilitação mediante a Lei n. ${ }^{\circ}$ 12.348/2007, que estabelece a equiparação das docências ainda de que de forma gradativa, parcelada até 2010. Isso se deu pela via organizativa da categoria.

Considerandoas condições objetivas detrabalho na RME, relativamente à jornada de trabalho e horaatividade, observou-se que as potencialidades de estas se constituírem em indicadores de qualidade, em tese, dependem da instituição, da dedicação exclusiva a uma mesma escola.

Em Curitiba 84\% dos profissionais têm contratação por concurso em vínculos de 20 horasaula, condição que pode traduzir em acúmulo de trabalho em redes e escolas diferenciadas. Isso requer um estudo mais detalhado. Entretanto, a empiria sugere que muitos profissionais, além da dobra na própria rede, podem fazer dupla e até mesmo uma tripla jornada de trabalho.

\section{Referências}

ABREU. D. C.; MOREIRA, C. R. B. S. PCCS: Valorização ou precarização do trabalho e da carreira do Magistério Público Municipal? Revista Chão da Escola, SISMMAC, Curitiba, v. 4, p. 31-36, 2005.

ABREU, D. C. Plano de cargos, carreira e salário do magistério público de Curitiba: Uma análise do processo de construção da Lei N. ${ }^{\circ}$ 10.190/2001. Monografia. Curitiba, 2005. 77 f. (Especialização em Organização do Trabalho Pedagógico) Setor de Educação, Universidade Federal do Paraná, Curitiba, 2005.

ABREU. D. C. Carreira e perfil do profissional do magistério na Rede Municipal de Ensino de Curitiba: História e impacto da política brasileira de valorização do magistério. Curitiba, 2008. 169f. Dissertação (Mestrado em Educação). Universidade Federal do Paraná, Curitiba, 2008.

BRASIL, Constituição (1988). Constituição: República Federativa do Brasil. Brasília, DF: Senado Federal, 1988. BRASIL, Ministério da Administração e da Reforma do Estado. Plano Diretor da Reforma do Aparelho do Estado, de novembro de 1995. Brasília, DF.

BRASIL, Ministério da Educação e Cultura. (1996). Lei de Diretrizes e Bases da Educação Nacional, de 20 de dezembro de 1996. Brasília, DF.

BRASIL, Ministério da Educação e Cultura. (1996). Lei 9.424/96 (FUNDEF). Dispõe sobre o Fundo de Manutenção e Desenvolvimento do Ensino Fundamental e de Valorização do Magistério, na forma prevista no art. $60, \S 7^{\circ}$, do Ato das Disposições Constitucionais Transitórias, e dá outras providências, de 24 de dezembro de 1996. Brasília, DF.

BRASIL, Ministério da Educação e Cultura, CNE, CEB. Resolução n. 3/1997. Fixa diretrizes para os novos planos de carreira e de remuneração para o Magistério dos estados, do Distrito Federal e dos municípios, de 8 de outubro de 1997. Brasília, DF.

BRASIL, Ministério da Educação, Instituto Nacional de Estudos e Pesquisas Educacionais Anísio Teixeira. Sinopse do Censo dos Profissionais da Educação Básica 2003. Brasília, DF, 2006.

CAMPOS, R. C. de. As políticas educacionais para o município de Curitiba no período de $1982-1993$. Dissertação (Mestrado em Educação) Setor de Educação, Universidade Federal do Paraná. 
CNTE. Cadernos de Educação. Magistério Público: Diretrizes para a Carreira e a Remuneração. 2. ed. Brasília, ano IV, n. 6, junho/1999.

CNTE. Cadernos de Educação. Magistério Público: Diretrizes para a Carreira e a Remuneração, Brasília, ano IV, n. 6, junho/1999. 2.ed. (Complemento do Caderno de Educação n. 6.)

CURITIBA, Câmara Municipal de Curitiba. Lei n. 4.789/1974. Estabelece Sistema de Classificação de Cargos, fixa número de cargos e níveis de vencimento e dá outras providências, de 11 de março de 1974. Curitiba, PR.

CURITIBA, Câmara Municipal de Curitiba. Lei Ordinária n. 7.671/1991. Dispõe sobre a Reorganização Administrativa do Poder Executivo do Município de Curitiba e dá outras providências, de 10 de junho de 1991. Curitiba, PR.

CURITIBA, Câmara Municipal de Curitiba. Lei Ordinária n. 6.761/1985. Dispõe sobre o Estatuto do Magistério Público Municipal, de 08 de novembro de 1985.

CURITIBA, Câmara Municipal de Curitiba. Lei Ordinária n. 7.704/1991. Altera dispositivos da Lei 7.671 de 10 de junho de 1991 e dá outras providências, de 23 de agosto de 1991.

CURITIBA, Câmara Municipal de Curitiba. Lei ordinária n. 8.785/1995. Altera a Lei N. 8.660, de 18 de dezembro de 1995.

CURITIBA, Câmara Municipal de Curitiba. Lei n. 10.190/2001. Institui o Plano de Carreira do Magistério Público Municipal, de 28 de junho de 2001.

CURITIBA, Câmara Municipal de Curitiba. Lei n. 12.348/2001. Altera dispositivos da Lei $\mathbf{N}^{\circ} \mathbf{1 0 . 1 9 0}^{\mathbf{1 0}}$, de 28 de junho de 2001, que "Institui o Plano de Carreira do Magistério Público Municipal”, de 16 de agosto de 2007.

CURITIBA, Câmara Municipal de Curitiba. Lei n. 10.190/2001. Que institui o plano de carreira do MAGISTÉRIO PÚBLICO MUNICIPAL, de 28 de junho de 2001.

CURITIBA, Câmara Municipal de Curitiba. Lei n. 6.761/1985. Dispõe sobre o Estatuto do Magistério Municipal, de 8 de novembro de 1985.

FARENZENA, N. A política de financiamento da educação básica: rumos da legislação brasileira. Porto Alegre: Editora da UFRGS, 2006.

GENTILI, P. Pedagogia da exclusão: o neoliberalismo e a crise da escola pública. Michael Apple et al. 10. ed. Petrópolis, RJ: Vozes, 2002.

MORDUCHOWWICZ, A. Carreira, incentivos e estruturas salariais docentes. PREAL/BRASIL, 2003.

MURILO, J. Um panorama sobre a carreira docente na América Latina: sistemas de reconhecimento e promoção do desempenho profissional. Revista PRELAC. Unesco, 2005.

PERONI, V. Política educacional e o papel do Estado no Brasil dos anos 90. São Paulo: Xamã, 2003.

SILVEIRA, M. H. Associação do Magistério Municipal de Curitiba: Origem e Desenvolvimento - 1979 a 1985. São Paulo, 1991. 122 f. Dissertação (Mestrado em Educação). Pontifícia Universidade Católica de São Paulo, São Paulo, 1991.

SOARES, K. C. D. A política de qualificação em serviço dos professores da rede municipal de ensino de Curitiba na gestão Greca (1993- 1996): entre o discurso da "cultura das elites" e a perspectiva pragmática do trabalho educativo. Curitiba, 2003. 242 f. Dissertação (Mestrado em Educação). Universidade Federal do Paraná, Curitiba, 2003.

VIEIRA, J. D. Piso salarial profissional nacional dos educadores: dois séculos de atraso. Brasília: LGE, 2007.

Identidade expropriada: Retrato do Educador Brasileiro. Brasília: CNTE, 2004.

Recebido em abril de 2009.

APROVADO EM MAIO DE 2009. 